"Non-viral mediated gene therapy in human cystic fibrosis airway epithelial cells recovers chloride channel functionality."Sainz-Ramos, M., Villate-Beitia, I., Gallego, I., AL Qtaish, N., Lopez-Mendez T.B., Eritja, R., Grijalvo, S., Puras, G., Pedraz, J.L. Int. J. Pharm., 588, 119757 (2020). PMID: 32791297, doi: 10.1016/j.ijpharm.2020.119757

\title{
Non-viral mediated gene therapy in human cystic fibrosis airway epithelial cells recovers chloride channel functionality
}

Myriam Sainz-Ramos ${ }^{a, b}$, Ilia Villate-Beitiaa,b, Idoia Gallego ${ }^{a, b}$, Nuseibah A.L. Qtaish $^{a}$, Tania B. Lopez-Mendeza, ${ }^{b}$, Ramón Eritja ${ }^{b, c}$, Santiago Grijalvo ${ }^{b, c}$, Gustavo Puras ${ }^{a, b, *}$, José Luis Pedraz ${ }^{a, b, *}$

${ }^{a}$ NanoBioCel Group, University of the Basque Country (UPV/EHU), VitoriaGasteiz, Spain

${ }^{\mathrm{b}}$ Biomedical Research Networking Center in Bioengineering, Biomaterials and Nanomedicine (CIBER-BBN), Spain

'Institute of Advanced Chemistry of Catalonia (IQAC-CSIC), Barcelona, Spain

Abbreviations: CF, cystic fibrosis; CFTR, cystic fibrosis transmembrane conductance regulator; pEGFP, plasmid with enhanced green fluorescent protein; FITC, fluorescence isothiocyanate; TEM, transmission electron microscopy; CME, clathrin mediated endocytosis; CVME, caveolae mediated endocytosis; SPQ, 6-methoxy-N-(3-sulfopropyl) quinolinium; FSK, forskolin; IBMX, 3-isobutyl-1-methylxanthine.

Keywords: Gene therapy, Non-viral, Niosomes, CFTR, Cystic fibrosis.

* Corresponding authors at: Laboratory of Pharmacy and Pharmaceutical Technology, School of Pharmacy, University of the Basque Country (UPV/EHU), Paseo de la Universidad 7, 01006 Vitoria-Gasteiz, Spain. E-mail addresses: gustavo. puras@ehu.eus (G. Puras), joseluis.pedraz@ehu.es (J.L. Pedraz)

\section{ABSTRACT}

Gene therapy strategies based on non-viral vectors are currently considered as a promising therapeutic option for the treatment of cystic fibrosis (CF), being liposomes the most commonly used gene carriers. Niosomes offer a powerful alternative to liposomes due to their higher stability and lower cytotoxicity, provided by their nonionic surfactant and helper components. In this work, a three-formulation screening is performed, in terms of physicochemical and biological behavior, in CF patient derived airway epithelial cells. The most efficient niosome formulation reaches $28 \%$ of EGFP expressing live cells and follows caveolae-mediated endocytosis. Transfection with therapeutic cystic fibrosis transmembrane conductance regulator (CFTR) gene results in 5-fold increase of CFTR protein expression 
in transfected versus non-transfected cells, which leads to 1.5-fold increment of the chloride channel functionality. These findings highlight the relevance of niosome-based systems as an encouraging non-viral gene therapy platform with potential therapeutic benefits for CF.

\section{I ntroduction}

Nowadays, some gene therapy products have already reached approval for human use and are commercially available (Dunbar et al., 2018). Therefore, this kind of strategy is recognized as a realistic medical option for the treatment of both inherited and acquired human diseases. However, in order to make gene therapy evolve into a leading therapeutic option in clinical practice, still some relevant issues need to be addressed, especially those related to the design and development of safe and effective gene carriers.

Gene therapy results particularly attractive for the treatment of inherited and monogenic diseases such as cystic fibrosis (CF), an autosomal recessive condition, caused by different mutations in the cystic fibrosis transmembrane conductance regulator (CFTR) gene. Although the gene was identified more than 30 years ago, currently, there is no curative treatment (Cooney et al., 2018). New pharmaceuticals such as Kalydeco ${ }^{\circledR}$ (ivacaftor), Orkambi $^{\circledR}$ (lumacaftor/ ivacaftor), and Symdeko ${ }^{\circledR}$ (tezacaftor/ ivacaftor) have given substantial benefit to some people with CF, contributing to improve both quality and expectancy of life (Donnelley and Parsons, 2018). Although these approaches alleviate or minimize the consequences of CF, they are not able to repair the underlying genetic defect. In this sense, gene therapy is aimed at transferring correct copies of the CFTR gene into airway epithelial cells, targeting the genetic origin of the disease. Earliest clinical trials in CF patients have established proof-of-principle for transfer of the wild-type CFTR gene to human airway epithelial cells using liposome based nonviral vectors (Alton et al., 2015). Therefore, non-viral gene therapy for CF could become a real medical option as an alternative to viral vectors, due to relevant advantages including, among others, high nucleic acid packing capacity required to deliver CFTR gene, low immunogenicity which allows repeated dose administration and low costs that allow the access of gene therapy products to the general population (Pezzoli et al., 2012).

Among the wide variety of nanosized materials that can be employed to develop non-viral vectors, cationic lipid based niosomes are considered promising candidates for gene delivery purposes due to their high biocompatibility and long-term stability (Ojeda et al., 2016). The preparation of these formulations requires three main components: a cationic lipid - to allow electrostatic interactions with negatively charged biomolecules such as DNA (Karmali and Chaudhuri, 2007), a helper component - to improve the biological performance of the formulation (Dabkowska et al., 2012) and non-ionic surfactants - to prevent particle aggregation and enhance the stability of the formulation (Liu et al., 1996). Different combinations of those components, along with the variety in their chemical composition, affect to the physicochemical parameters of niosome formulations, including size, surface charge and morphology. In turn, these characteristics determine the biological properties of niosomes, such as their cellular uptake, intracellular trafficking and the ability to deliver the 
DNA cargo in suitable subcellular compartments (Dabkowska et al., 2012). Along with the design of proper non-viral vectors for gene therapy purposes, the size and composition of the genetic material to deliver have to be considered. In this sense, several efforts have been conducted in order to enhance the performance of conventional plasmids, including the removal of bacterial backbones, the optimization of the promoters or the elimination of CpG islands, which confer not only lower immunogenicity but also higher transfection efficiencies and sustained transgene expression (Gallego et al., 2019; Hyde et al., 2008). The therapeutic pGM169 plasmid, which encodes for a correct copy of the CFTR gene, is currently used in CF clinical trials as an optimized gene construct vectored by liposome based non-viral vectors (Alton et al., 2015; Hyde et al., 2008). In this regard, niosome based formulations offer a promising alternative to liposomes due to their enhanced stability and lower cytotoxicity, provided by the non-ionic surfactant and the helper component (Bartelds et al., 2018; Choi et al., 2004).

Taking all those factors into account, our goal was to develop a suitable non-viral formulation based on niosomes able to transfer efficiently correct copies of the CFTR gene into human CF airway epithelial cells. For that purpose, in this work, we designed and prepared niosome formulations 1, 2 and 3 - named as N1, N2 and N3 - based on different cationic lipids, helper components and non-ionic surfactants. The resulting niosomes were bound to different DNA constructs of interest, depending on the assay, to form the corresponding nioplexes. Niosomes and nioplexes were physicochemically characterized in terms of size, dispersity, zeta potential and morphology. In vitro experiments were carried out in human CF airway epithelial cells to evaluate the transfection efficiency and cell viability, as well as the cellular uptake and intracellular trafficking of nioplexes. Additionally, transfection efficiency was further evaluated through both, the CFTR transgene and protein quantification and the biological activity of the CFTR channel.

\section{Materials and methods}

\subsection{Preparation of niosomes and nioplexes}

Niosome formulations were prepared by the oil-in-water emulsion technique as previously described (Ojeda et al., 2016). Fig. 1 indicates the chemical structure (Fig. 1A) and the components used for the elaboration of N1, N2 and N3 formulations (Fig. 1B) and a general scheme showing the distribution of the components in niosomes (Fig. 1C). The organic phase of $\mathrm{N} 1$ and N2 contained the cationic lipid 1,2-di-O-octadecenyl-3trimethylammonium propane (DOTMA) $(6.7 \mathrm{mg})$ (Avanti Polar Lipids, USA) and helper lipid squalene $(19 \mu \mathrm{L})$ (Sigma-Aldrich, USA) dissolved in dichloromethane (DCM) (1 mL) (Panreac, Spain). In contrast, the organic phase of N3 contained the cationic lipid 2,3-di(tetradecyloxy)propan-1amine (DTPA) (5 mg) tailor-synthesized (Ojeda et al., 2016), non-ionic surfactants polysorbate $80(12.5 \mathrm{mg})$ (Panreac, Spain) and poloxamer 407 (12.5 mg) (Sigma-Aldrich, USA), all dissolved in DCM (1 mL). The water phase of $\mathrm{N} 1$ and $\mathrm{N} 2$ contained, respectively, polysorbate $20(0.49 \%)$ (Sigma-Aldrich, USA) and polysorbate $80(0.52 \%)$ dissolved in distilled 
water $(5 \mathrm{~mL})$. The water phase of $\mathrm{N} 3$ contained the helper component chloroquine diphosphate salt $(2.5 \mathrm{mg})$ (Sigma-Aldrich, USA) dissolved in distilled water $(5 \mathrm{~mL})$. In all formulations, the organic phase and the water phase were emulsified by sonication (Branson Sonifier 250, Danbury) for 30 $\mathrm{s}$ at $50 \mathrm{~W}$. The organic solvent was removed from the emulsion by evaporation under magnetic agitation for $1 \mathrm{~h}$ at room temperature.

The nioplexes were formed by mixing an appropriate volume of a stock solution of DNA with different volumes of the niosome formulation to obtain, the following cationic lipid/DNA mass ratios: 2/1, 5/1 and 10/1. Niosomes and DNA were incubated for $30 \mathrm{~min}$ at room temperature to enhance electrostatic interactions and allow the formation of nioplexes.

A

Cationic lipids

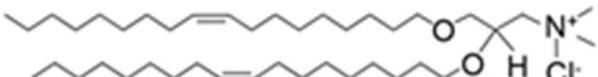

1,2-di-O-octadecenyl-3-trimethylammonium propane (DOTMA)

\ Non-ionic surfactants<smiles>C/C=C\CCCCCCCC(=O)OCCOCC(OCCO)C1OCC(OCCO)C1OCCO</smiles>

Polysorbate 80<smiles>CC(C)OC(C)(C)CC(C)(C)OCC(C)(C)O</smiles>

Poloxamer 407

$\checkmark$ Helper components<smiles>CC(C)CCC(C)CCC(C)CCC(C)CCCCCCC(C)(C)C</smiles>

Squalene

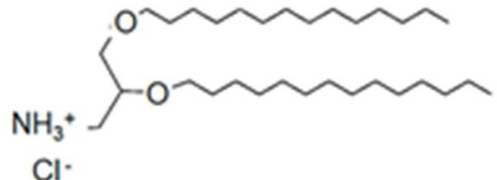

2,3-di(tetradecyloxi)propan-1-amine (DTPA)

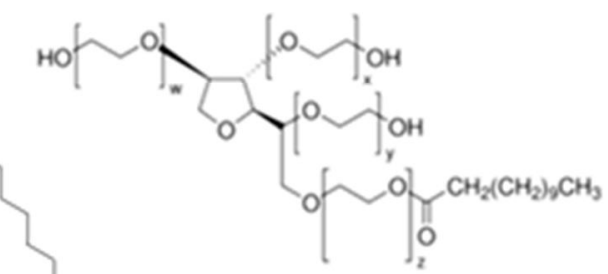

Polysorbate 20<smiles>CCN(CC)CCCC(C)Nc1ccnc2cc(Cl)ccc12</smiles>

Chloroquine

\begin{tabular}{|c|c|c|c|c|c|c|c|c|}
\hline & \multicolumn{2}{|c|}{ Cationic lipids } & \multicolumn{3}{|c|}{ INon-ionic surfactant } & \multicolumn{2}{|c|}{$\triangle$ Helper components } \\
\hline & & \multirow{2}{*}{ DOTMA } & \multirow{2}{*}{ DTPA } & \multicolumn{2}{|c|}{ Polysorbate } & \multirow{2}{*}{$\begin{array}{c}\text { Poloxamer } \\
407\end{array}$} & \multirow{2}{*}{ Squalene } & \multirow{2}{*}{ Chloroquine } \\
\hline & & & & 20 & 80 & & & \\
\hline \multirow{3}{*}{ 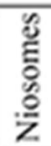 } & $\mathrm{N} 1$ & $\checkmark$ & & $\checkmark$ & & & $\checkmark$ & \\
\hline & N2 & $\checkmark$ & & & $\checkmark$ & & $\checkmark$ & \\
\hline & N3 & & $\checkmark$ & & $\checkmark$ & $\checkmark$ & & $\checkmark$ \\
\hline
\end{tabular}

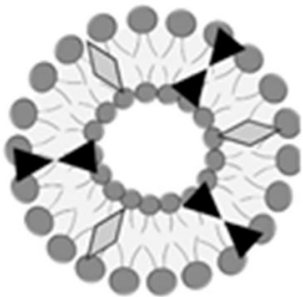

Fig. 1. Overview of niosomes N1, N2 and N3. A. Chemical structures of the components. B. Description of the components that constitute each niosome. C. General scheme of the disposition of components in a niosome.

\subsection{Genetic material}


Four plasmid constructs DNA were used in this work: pCMS-EGFP ( 5.5 $\mathrm{kb}$, PlasmidFactory, Germany), fluorescence isothiocyanate (FITC) labelled pCMS-EGFP (DareBio, Spain), pEGFP-CFTR (9.1 kb, kindly provided by Unit of Viral Infections and Comparative Pathology at University of Lyon 1) and pGM169 (6.5 kb, CpG free CFTR plasmid kindly gifted from Professor Deborah Gill and co-workers at the University of Oxford from UK Cystic Fibrosis Consortium).

pCMS-EGFP, named as pEGFP, was used for the initial formulation screening assays. FITC labelled pCMS-EGFP, named as FITC-pEGFP, was used for cellular uptake and intracellular trafficking studies. pEGFPCFTR and pGM169 were used for gene transfection efficiency and CFTR channel functional assessment.

The pEGFP and pEGFP-CFTR plasmids used in this work were propagated in Escherichia coli $\mathrm{DH} 5 \mathrm{a}$ and One Shot ${ }^{\mathrm{TM}} \mathrm{StbL}^{\mathrm{TM}}$ chemically competent Escherichia coli, respectively, and purified using the Qiagen endotoxin-free plasmid purification Maxi-prep kit (Qiagen, Santa Clarita, CA, USA) according to manufacturer's instructions. The concentration of pDNA was quantified by measuring the absorbance at $260 \mathrm{~nm}$ with a SimpliNano ${ }^{\mathrm{TM}}$ device (GE Healthcare, Buckinghamshire, UK).

\subsection{Size, dispersity, zeta potential and morphology}

The hydrodynamic diameter, which includes the particle size and dispersity $(\Xi)$, and the zeta potential of both niosomes and their corresponding nioplexes were determined by Dynamic Light Scattering (DLS) and by Lasser Doppler Velocimetry (LDV), respectively, using a Zetasizer Nano ZS (Malvern Instrument, UK) and the morphology of niosomes was determined by transmission electron microscopy (TEM), all as previously described (Puras et al., 2014).

\subsection{Cell culture and transfection assays}

Human CF airway epithelium cells (CuFi-1) (ATCC ${ }^{\circledR}$ CRL- $4013^{\mathrm{TM}}$ ), a specific CF patient derived cell model homozygous for the $\Delta \mathrm{F} 508$ mutation (Buchanan et al., 2013) were grown in bronchial epithelial growth medium -2 bulletkit- (BEGM) (Lonza, Basel, Switzerland) previous flask/plate pretreatment with collagen type IV (Sigma-Aldrich, USA). Cells were incubated at $37{ }^{\circ} \mathrm{C}$ and $5 \% \mathrm{CO}_{2}$ atmosphere, and were split every 3-4 days to maintain monolayer coverage.

For transfection efficiency assays, cells were seeded in 24 well plates at a density of $1.6 \times 105$ cells per well and incubated overnight to achieve $70 \%$ of confluence at the time of transfection with nioplexes at cationic lipid/DNA mass ratio $2 / 1,5 / 1$ and $10 / 1$. For that purpose, electrostatic interactions between the cationic lipid and the corresponding plasmid were left to occur for $30 \mathrm{~min}$ at room temperature in OptiMEM (Gibco, San Diego, CA, USA) transfection medium. Once removing the growth medium from the plate, cells were exposed for $4 \mathrm{~h}$ to nioplexes containing DNA (1.25 $\mathrm{\mu g}$ per well). After the incubation, nioplexes were removed and fresh medium was added to the cells. Transfection efficiency was analyzed $48 \mathrm{~h}$ after the exposure to nioplexes. Lipofectamine ${ }^{\mathrm{TM}} 2000$ transfection reagent (Invitrogen, Carlsbad, CA, USA) was used as positive control. Transfection negative control cells were not exposed to nioplexes, but were incubated in OptiMEM for $4 \mathrm{~h}$. Each condition was performed in triplicate. 


\subsection{Analysis of EGFP expression and cell viability}

Qualitative analysis of EGFP signal was conducted using an inverted microscope equipped with an attachment for fluorescence observation (EclipseTE2000-S, Nikon). For quantitative determination of EGFP expression and cell viability, flow cytometry analysis was conducted using a FACSCalibur system flow cytometer (Becton Dickinson Bioscience, San J ose, USA). For that purpose, N1, N2 and N3 nioplexes-transfected cells were washed with Dulbeccós phosphate buffered saline (DPBS) with calcium and magnesium (Lonza, Basel, Switzerland) and detached with trypsin/EDTA (200 $\mu \mathrm{L}$ per well, 0.25\%) (Gibco, San Diego, CA, USA). Trypsin inhibitor ( $500 \mu \mathrm{L}$ DPBS with $1 \%$ of fetal bovine serum) (Gibco, San Diego, CA, USA) were added and cells were centrifuged at $1100 \mathrm{rpm}$ for $5 \mathrm{~min}$. The resulting pellet was resuspended in BEGM $(500 \mu \mathrm{L})$ and transferred to specific flow cytometer tubes. Cell viability was evaluated using propidium iodide (Sigma-Aldrich, USA) at 1:300 dilution in each sample. The fluorescent signals corresponding to dead cells and to EGFP positive cells were measured at $650 \mathrm{~nm}$ (FL3) and $525 \mathrm{~nm}$ (FL1), respectively. Non-transfected cells, used as control samples, were displayed on a forward scatter (FSC) versus side scatter (SSC) dot plot to establish a collection gate and exclude cells debris. Positive transfection control samples transfected with Lipofectamine $^{\mathrm{TM}} 2000$ were used to establish cytometer settings and channel compensations. Cell viability data were normalized in relation to the value of non-transfected control cells. The experiments were carried out in triplicate for each condition. For each sample 10,000 events were collected.

\subsection{Cellular uptake}

The cellular internalization of nioplexes bound to FITC-pEGFP was analysed both qualitatively and quantitatively by fluorescence microscopy and flow cytometry, respectively. For qualitative assays, human CF cells were seeded on coverslips in 24 well plates and transfected with nioplexes for $4 \mathrm{~h}$. After that, cells were washed with phosphate buffered saline (PBS, Gibco, San Diego, CA, USA) and fixed with 4\% formaldehyde (Panreac, Spain). Then, cells were washed twice with PBS and incubated for 40 min with phalloidin $(5 \mu \mathrm{L})$ diluted in a $1 \%$ bovine serum albumin (BSA) in PBS solution to stain cells cytoskeleton. Once washing with PBS, cells were mounted with Fluoroshield ${ }^{\mathrm{TM}}$ with DAPI (Sigma-Aldrich, USA) and observed under Zeiss Axio Observer fluorescence microscopy with Apotome 2 illumination system (Zeiss Axiobserver, Jena, Germany). Captured images were analysed with ImageJ software.

For quantitative analyses, a FACSCalibur system flow cytometer was used to quantify the percentage of cells that contained FITC-labelled EGFP coding plasmid DNA. Cells were detached and processed for flow cytometry measurements as previously mentioned. Cellular uptake was expressed as the percentage of FITC-labeled plasmid positive cells after excluding dead cells and analysed as described above.

\subsection{Intracellular trafficking}

For cellular internalization assays, human CF cells were transfected with the FITC-labeled pEGFP for $3 \mathrm{~h}$ over coverslips, as aforementioned. Then, the following endocytic vesicle markers were added and incubated for $1 \mathrm{~h}$ with either Transferrin-AlexaFluor594 (50 $\left.\mathrm{g} \mathrm{m} \mathrm{m}^{-1}\right)$, Cholera toxin BAlexaFluor594 $\left(10 \mu \mathrm{g} \mathrm{mL} \mathrm{m}^{-1}\right)$ or Dextran-AlexaFluor594 $\left(1 \mu \mathrm{g} \mathrm{LL}^{-1}\right)$, which 
are markers for clathrin mediated endocytosis (CME), caveolae mediated endocytosis (CVME) and macropinocytosis, respectively. After that, cells were washed with PBS, and then, they were fixed, mounted with and observed under fluorescence microscopy as described above. Co-localization of the green and red signal was analyzed by ImageJ software and quantified by a cross-correlation analysis, as previously described (van Steensel et al., 1996; Villate-Beitia et al., 2018). Incubation with the endocytic vesicle markers without previous transfection with FITC-pEGFP was carried out to determine the quantity of clathrins, caveolae or macropinocytosis vesicles in human CF cells by flow cytometry analyzing 10,000 events per sample.

\subsection{CFTR protein quantification}

The protein expression of CFTR (150-170 kDa) from cell cultures was analyzed by Western blot. For that, cells were seeded in 6 well plates at a cell density of $8 \times 105$ per well and transfected with nioplexes vectoring pGM169. After trypsinization and centrifugation, total protein was extracted from the resulting pellet with lysis buffer (TRIS $1 \mathrm{mM}, \mathrm{NaCl} 15 \mathrm{mM}$, EDTA $0.2 \mathrm{mM}, 2 \%$ Triton X-100) and protease inhibitor EDTA-free cocktail 1\% (Roche, Germany), which was then placed on ice for $30 \mathrm{~min}$. After that, the contents were centrifuged for $10 \mathrm{~min}(10,000 \mathrm{~g})$ at $4{ }^{\circ} \mathrm{C}$ and the supernatant was employed for protein quantification by a Pierce $^{\mathrm{TM}}$ BCA protein assay kit (Thermo Fisher, USA), according to the manufacturer instructions. Protein containing Laemmli buffer $(30 \mu \mathrm{g})$ (Bio-Rad, USA) was loaded into a SDS-PAGE, 7\% acrylamide, midi-PROTEAN ${ }^{\circledR}$ TGX $^{\mathrm{TM}}$ electrophoresis gel (Bio-Rad, USA) and separated at $130 \mathrm{~V}$ for $75 \mathrm{~min}$. Proteins were transferred in a semi-dry system (Trans-Blot ${ }^{\circledR}$ Turbo ${ }^{\mathrm{TM}}$ Transfer System, Bio-Rad, USA) to a PVDF membrane which was then blocked with $5 \%$ non-fat milk in TBST $0.1 \%$ for $1 \mathrm{~h}$ at room temperature.

A monoclonal mouse anti-human/-mouse against CFTR (CF3; Thermo Fisher, USA) at a dilution of 1:500 in blocking solution, was incubated with the membrane overnight at $4{ }^{\circ} \mathrm{C}$. Bands were detected using peroxidaseconjugated goat anti-mouse IgG (1: 10,000; Bio-Rad, USA) secondary antibody diluted in blocking solution. Wash steps were carried out with TBST $0.1 \%$. Specific protein expression was detected by chemiluminescence with ECL Plus (Bio-Rad, USA) and observed in a ChemiDoc System (Bio-Rad, USA). $\beta$-actin was used as a loading control, employing a rabbit polyclonal anti $\beta$-actin antibody (1: 400, Abcam) followed by peroxidase-conjugated secondary antibody (1: 20,000, GE Healthcare, UK). Densitometric evaluation of bands was performed using the Image Lab 4.0.1 software. Data were expressed as arbitrary densitometric units (ADU) relative to $\beta$ actin expression.

\subsection{CFTR channel functionality}

For CFTR channel functionality, human CF cells were seeded in a 96 well plate at a density of $3 \times 10^{4}$ cells and incubated overnight. Cells were transfected with nioplexes vectoring pGM169. After 48 h, CFTR chloridechannel activity was measured by monitoring iodide efflux evolution along time, which is commonly used as surrogate for chloride (Mitomo et al., 2010). For that purpose, cells were washed twice with Hanḱs Balanced Salt Solution (HBSS) and incubated for 45 min with 6-methoxy-N-(3sulfopropyl) quinolinium (SPQ) (10 mM) fluorescent molecule (ThermoFisher Scientific, USA) diluted in 1:1 Nal buffer: Milli- $Q \circledR$ water hypotonic solution. 
Then, cells were washed with the Nal buffer [ Nal (130 mM), $\mathrm{KNO}_{3}(4 \mathrm{mM})$, $\mathrm{Mg}\left(\mathrm{NO}_{3}\right)_{2}(1 \mathrm{mM}), \mathrm{Ca}\left(\mathrm{NO}_{3}\right)_{2}(1 \mathrm{mM})$, glucose (10 mM) (Sigma-Aldrich, USA) and 4-(2-hydroxyethyl)-1-piperazineethanesulfonic acid (HEPES) (20 mM) (Lonza, Basel, Switzerland) in MilliQ ${ }^{\circledR}$ water $(200 \mathrm{~mL})$ ] and incubated for 30 min in fresh Nal buffer. After that, cells were washed again twice with the $\mathrm{Nal}$ buffer and incubated for $20 \mathrm{~min}$ in nitrate buffer, which consisted of Nal buffer but replacing $\mathrm{Nal}$ by $\mathrm{NaNO}_{3}(130 \mathrm{mM})$ and supplemented with the CFTR channel agonists forskolin (FSK) $(10 \mu \mathrm{M})$ and 3-isobutyl-1methylxanthine (IBMX) $(200 \mu \mathrm{M})$ (Sigma-Aldrich, USA). In order to revert the basal state, nitrate buffer was replaced by Nal buffer. The fluorescent signal emitted by SPQ $(n \geq 5)$ was read at $443 \mathrm{~nm}$ in an Infinite M200 microplate reader (TECAN Trading AG. Männedorf, Switzerland) employing the Tecan i-control 1.7 software.

\subsection{Statistical analysis}

Statistical analysis was carried out using IBM SPSS Statistics 25 software. Normal distribution of samples was assessed by the KolmogorovSmirnov test, and the homogeneity of the variance by the Levene test. Under parametric conditions, one-way ANOVA followed by post-hoc HSD Tukey test was performed. Otherwise, the non-parametric Kruskal-Wallis test followed by Mann Whitney-U test for 2-2 comparisons was employed. In all cases, $p$ values $\leq 0.05$ were regarded as significant. Data were presented as mean \pm standard deviation (SD).

\section{RESULTS}

\subsection{Screening of formulations in terms of physicochemical characterization}

Based on previous experiments (Mashal et al., 2017; Ojeda et al., 2016; Puras et al., 2014), we selected and prepared three niosomes N1, N2 and N3 as starting formulations for the preparation of nioplexes. N1 and N2 contained DOTMA as cationic lipid and squalene as helper lipid (Fig. 1). They differ in the use of Polysorbate 20 (N1) or Polysorbate 80 (N2) as nonionic surfactant. Niosome N3 was prepared using DTPA as cationic lipid, chloroquine as helper component and Polysorbate 80 and Poloxamer 407 as non-ionic surfactants.

The physicochemical analysis of formulations revealed that the mean particle size of N1, N2 and N3 niosomes were $153.47 \pm 0.76 \mathrm{~nm}, 144.17 \pm$ $1.89 \mathrm{~nm}$ and $106.93 \pm 0.31 \mathrm{~nm}$, respectively (Fig. 2A, bars). Upon the addition of pEGFP at cationic lipid/ DNA mass ratios $2 / 1,5 / 1$ and $10 / 1$, the mean particle size values remained similar in N1, meanwhile slightly increased in $\mathrm{N} 2$ and $\mathrm{N} 3$ at $2 / 1$ ratio and steadily decreased when augmenting the cationic lipid/DNA ratio (Fig. 2A, bars). Zeta potential values of N1, N2 and N3 niosomes were $+57.03 \pm 0.51 \mathrm{mV},+72.43 \pm 2.16$ $\mathrm{mV}$ and $+36.40 \pm 3.00 \mathrm{mV}$, respectively (Fig. 2A, dots). After complexing to pEGFP, zeta potential values of the three nioplexes at cationic lipid/DNA mass ratio $2 / 1$ decreased moderately, but increased again with augmenting cationic lipid/DNA mass ratios. As represented in Fig. 2B, all formulations showed low dispersity $(\boxplus)$ values, below 0.4 . 
A)

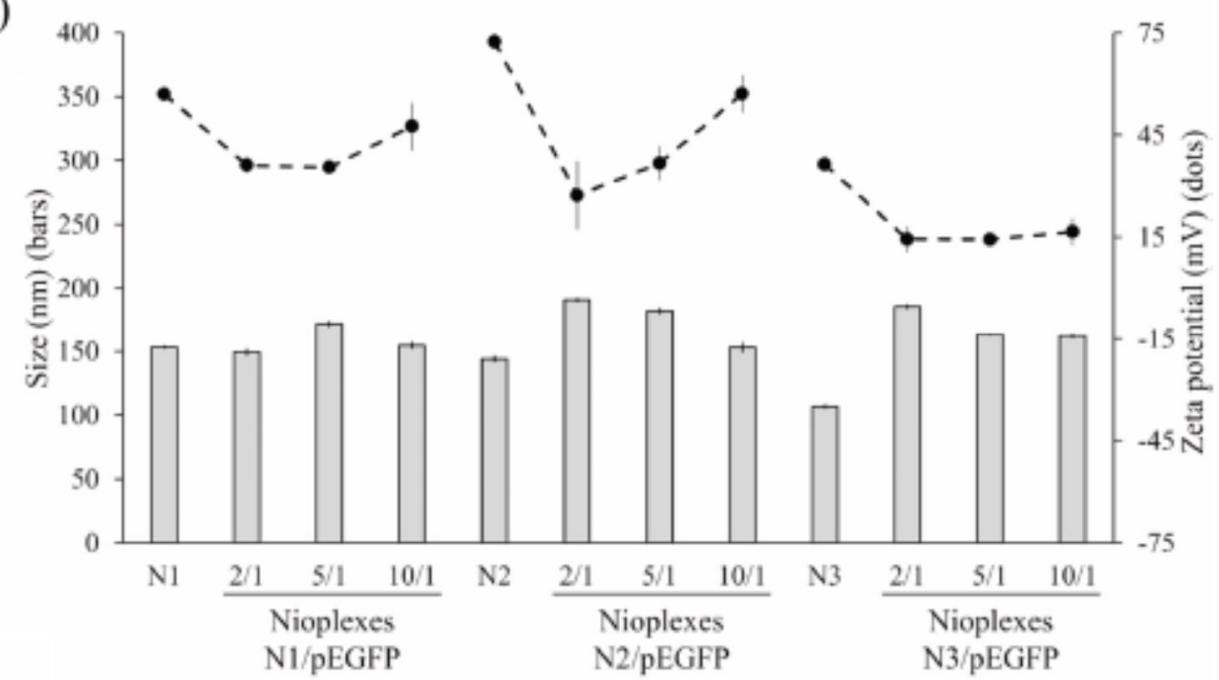

B)

\begin{tabular}{|c|c|c|c|c|c|c|c|c|c|c|c|c|}
\hline & \multirow{2}{*}{$\mathrm{Nl}$} & \multicolumn{3}{|c|}{$\begin{array}{l}\text { Nioplexes } \\
\text { N1/pEGFP }\end{array}$} & \multirow{2}{*}{$\mathrm{N} 2$} & \multicolumn{3}{|c|}{$\begin{array}{l}\text { Nioplexes } \\
\text { N2/pEGFP }\end{array}$} & \multirow{2}{*}{ N3 } & \multicolumn{3}{|c|}{$\begin{array}{c}\text { Nioplexes } \\
\text { N3/pEGFP }\end{array}$} \\
\hline & & $2 / 1$ & $5 / 1$ & $10 / 1$ & & $2 / 1$ & $5 / 1$ & $10 / 1$ & & $2 / 1$ & $5 / 1$ & $10 / 1$ \\
\hline Mean $\emptyset$ & 0.14 & 0.21 & 0.26 & 0.18 & 0.21 & 0.34 & 0.39 & 0.32 & 0.16 & 0.36 & 0.37 & 0.32 \\
\hline SD & 0.01 & 0.03 & 0.01 & 0.01 & 0.01 & 0.01 & 0.03 & 0.02 & 0.01 & 0.02 & 0.01 & 0.01 \\
\hline
\end{tabular}

Fig. 2. Physicochemical characterization, transfection efficiency and cell viability of N1, N2 and N3 niosomes and nioplexes vectoring pEGFP at different cationic lipid/DNA mass ratios. A. Particle size (bars) and zeta potential (dots) of niosomes and their corresponding nioplexes. Each value represents the mean \pm SD of three measurements. B. Dispersity $(\boxplus)$ values of niosomes and their corresponding nioplexes. Each value represents the mean \pm SD of three measurements. C. Percentage of EGFP positive live cells (bars) and cell viability (dots) evaluated by flow cytometry. Data are presented as mean $\pm S D, n=3$. Statistical significance $* p \leq 0.05$ in terms of transfection efficiency. 
A)

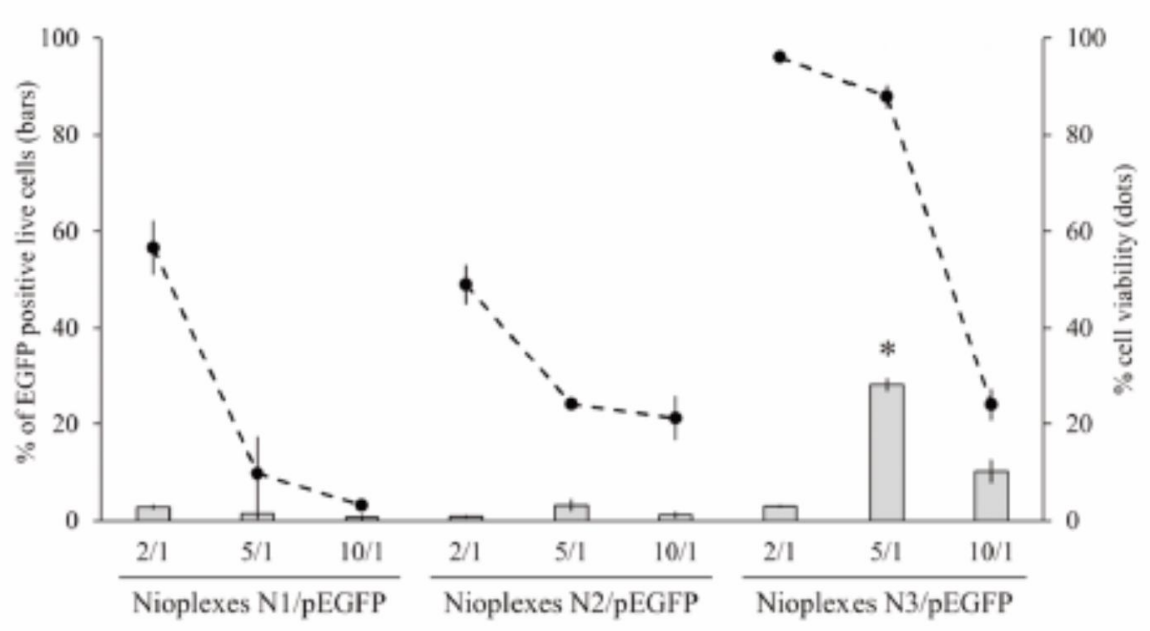

B)

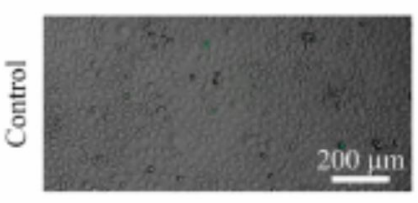

2/1
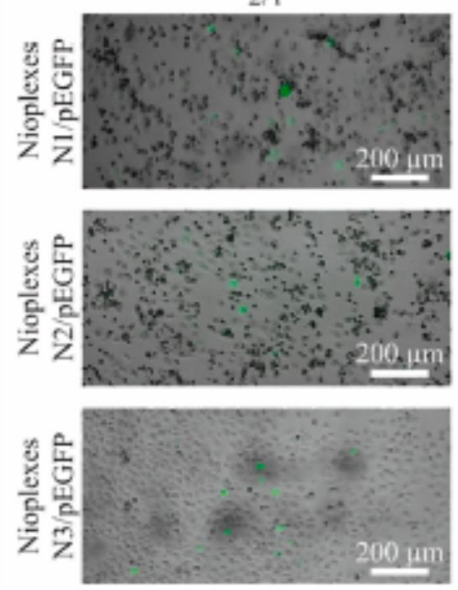

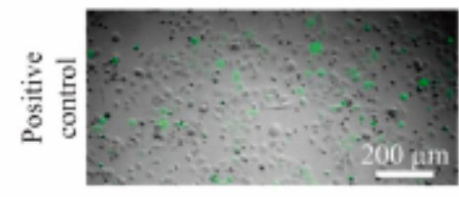

5/1
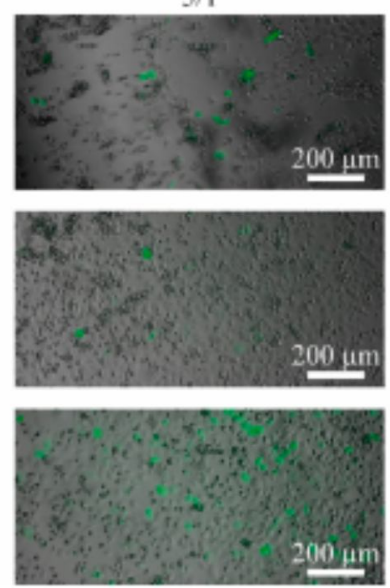

$10 / 1$
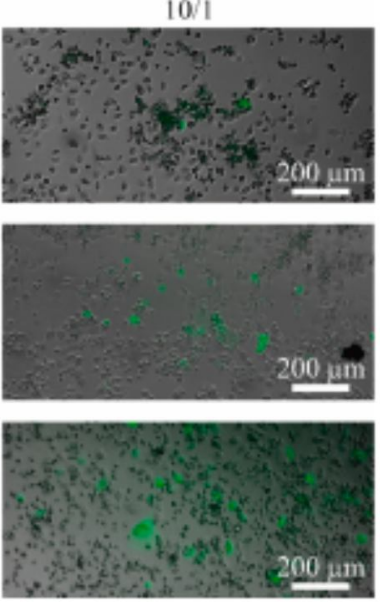

Fig. 3. Transfection efficiency and cell viability of N1, N2 and N3 niosomes and nioplexes vectoring pEGFP at different cationic lipid/DNA mass ratios in human CF airway epithelial cells. A. Percentage of EGFP positive live cells (bars) and cell viability (dots) evaluated by flow cytometry. Data are presented as mean $\pm S D, n=3$. Statistical significance $* p \leq 0.05$ in terms of transfection efficiency. B. Representative fluorescence microscope images of EGFP signal in human CF airway epithelial cells transfected with N1, N2 and N3 niosomes complexed with pEGFP at the indicated cationic lipid/DNA mass ratios. Control: non-transfected cells. Positive control: cells

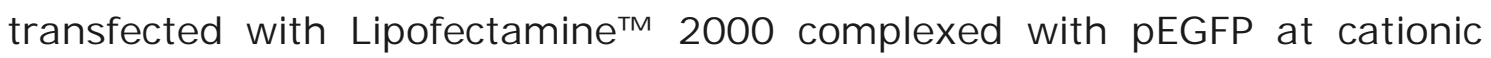
lipid/DNA mass ratio 2/1. Scale bar: $200 \mu \mathrm{m}$.

3.2. Screening of formulations in terms of transfection efficiency and cell viability 
Cell viability and transfection assays were performed with N1, N2 and N3 nioplexes vectoring pEGFP at cationic lipid/DNA mass ratios 2/ 1, 5/1 and $10 / 1$ in human CF airway epithelial cells (Fig. 3). For nioplexes N1 and $\mathrm{N} 2$, the percentage of EGFP expressing cells was lower than $5 \%$ in all cases and no significant differences were found when comparing the aforementioned ratios (Fig. 3A, bars). In the case of N3 nioplexes, transfection with cationic lipid/DNA mass ratio 5/1 achieved $28.14 \%$ of EGFP expressing cells, which was significantly higher ( $p \leq 0.05)$ than the values obtained with $2 / 1$ and $10 / 1$ ratios, as well as than values obtained with the rest of formulations (Fig. 3A, bars). Regarding cell viability, formulations containing $\mathrm{N} 1$ and N2 niosomes induced high cellular death of more than $50 \%$, while the formulation based on N3 niosomes at the cationic lipid/DNA mass ratio 5/1 presented high cell viability values near $90 \%$ (Fig. $3 \mathrm{~A}$, dots). In all cases, the 10/1 ratio caused higher cell death rates than their counterparts ratios. The transfection positive control Lipofectamine ${ }^{\mathrm{TM}}$ 2000 showed $38.02 \pm 4.16 \%$ of EGFP expressing live cells and a cellular viability of $50.77 \pm 5.01 \%$ (data not shown). The qualitative analysis of the transfection efficiency by the examination of cells under the microscope 48 $\mathrm{h}$ after transfection can be observed in Fig. 3B.

\subsection{Cellular uptake of N3 nioplexes}

Cellular uptake in terms of percentages of FITC positive live cells for N3 nioplexes vectoring FITC labelled pEGFP at the cationic lipid/DNA mass ratio $5 / 1$ was $75.11 \%$ at $2 \mathrm{~h}$ and $80.23 \%$ at $4 \mathrm{~h}$ post-exposure (Fig. 4A). Representative images of control and cells exposed to nioplexes for $4 \mathrm{~h}$ are shown in Fig. 4B. The transfection positive control Lipofectamine $^{\mathrm{TM}} 2000$ showed $86.53 \pm 0.63 \%$ and $84.60 \pm 2.70 \%$ of FITC positive live cells $2 \mathrm{~h}$ and $4 \mathrm{~h}$ after exposure to lipoplexes, respectively.

A)

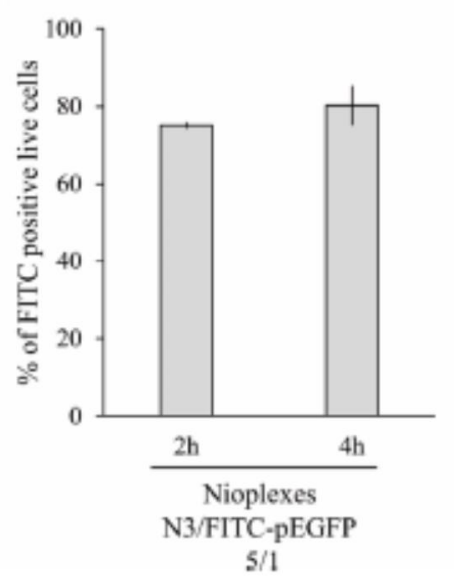

B)

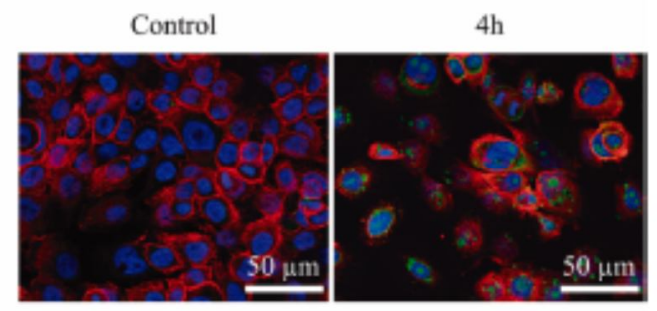

Fig. 4. Cellular uptake in human CF airway epithelial cells co-incubated with N3 nioplexes vectoring FITC labelled EGFP plasmid at 5/1 cationic lipid/DNA mass ratio. A. Percentage of FITC positive live cells after 2 and $4 \mathrm{~h}$ of incubation with N3 nioplexes, analysed by flow cytometry. Each value represents the mean $\pm S D, n=3$. B. Representative merged confocal microscopy images of cellular uptake. Cell nuclei were coloured in blue (DAPI); F-actin in red (Phalloidin); and N3 nioplexes in green (FITC). Scale bar: $50 \mu \mathrm{m}$. 


\subsection{Intracellular trafficking of N3 nioplexes}

The cellular internalization pathways studied in this work include clathrin-mediated endocytosis (CME), caveolae-mediated endocytosis (CVME) and macropinocytosis. The fluorescent signal emitted by the specific endocytic vesicle markers in human CF airway epithelial cells was higher for CvME and macropinocytosis than for CME (Fig. 5A). Colocalization analysis of these N3 nioplexes with the intracellular trafficking pathways showed the following mean CCF peak values: of $0.39 \pm 0.06$ with macropinocytosis markers, $0.13 \pm 0.02$ with CME markers and $0.36 \pm 0.01$ with CVME markers (Fig. 5B). Representative images of these conditions are shown in Fig. 5C.

A)

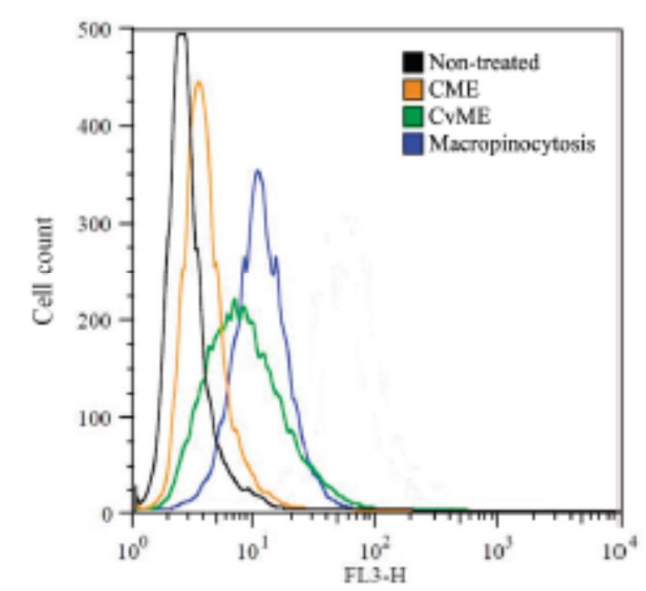

B)

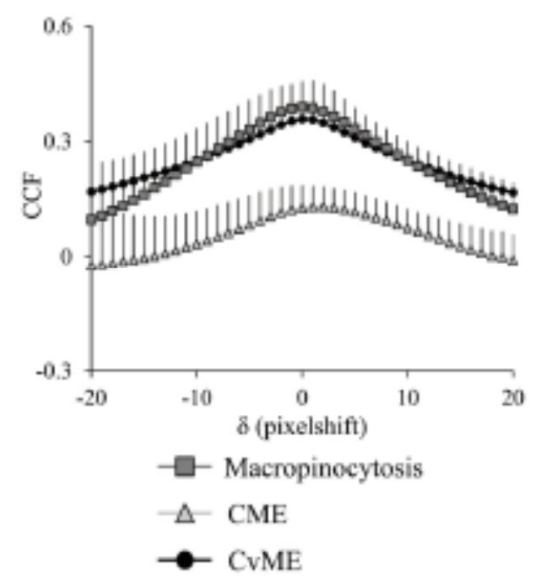

C)

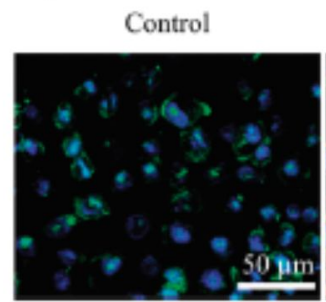

Macropinocytosis

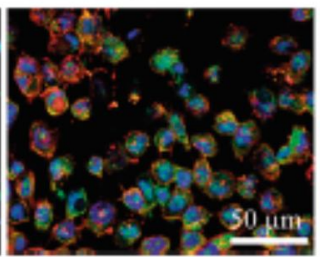

CME

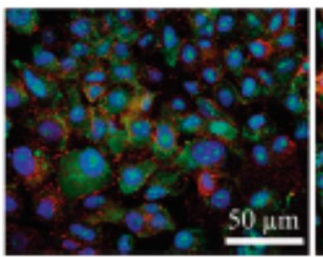

CrME

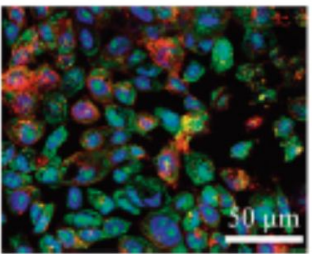

Fig. 5. Intracellular trafficking assays in human CF airway epithelial cells co-incubated with N3 nioplexes vectoring FITC labelled EGFP plasmid at 5/1 cationic lipid/ DNA mass ratio. A. Fluorescent signal of the endocytic vesicle markers by number of cells quantified by flow cytometry. B. Co-localization values of FITC labelled pEGFP and the endocytic pathways signals determined by cross-correlation analysis in each case. Each value represents the mean $\pm S D, n=3$. C. Representative merged confocal microscopy images of intracellular trafficking. Green colouring shows the FITC labelled EGFP plasmid, blue colouring shows cells nuclei stained with DAPI and red colouring shows one of the following endocytic vesicles: Dextran-Alexa Fluor 594 for macropinocytosis, Transferrin-Alexa Fluor 594 for clathrin mediated endocytosis (CME) and Cholera toxin B-Alexa Fluor 594 for caveolae mediated endocytosis (CvME). Scale bar: $50 \mu \mathrm{m}$. 
The physicochemical characterization of N3 niosome formulations vectoring the CFTR gene at the established 5/1 cationic lipid/DNA mass ratio (Fig. 6A) showed similar patterns to those observed in N3 vectoring pEGFP. Precisely, N3/pEGFP-CFTR and N3/pGM169 nioplexes showed mean size values of $168.47 \mathrm{~nm}$ and $155.1 \mathrm{~nm}$ and mean zeta potential values of $+13.6 \mathrm{mV}$ and $+21.77 \mathrm{mV}$, respectively (Fig. 6B). Mean $\oplus$ values were below 0.4 in all cases (Fig. 6C). When observed under TEM, N3 niosomes showed a clear spherical morphology (Fig. 6D).

A)

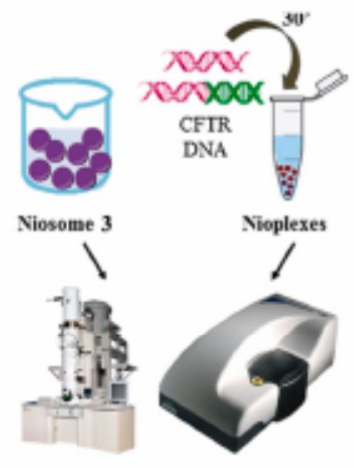

B)

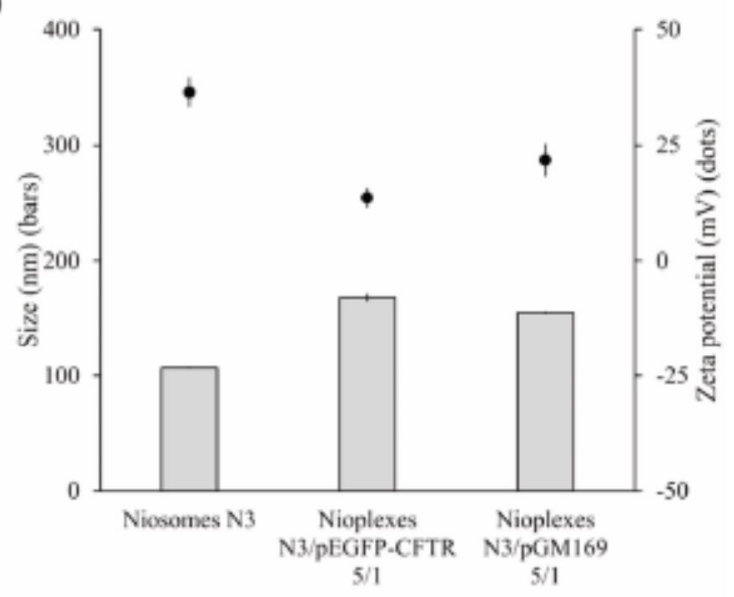

D)

\begin{tabular}{|c|cc|}
\cline { 2 - 3 } \multicolumn{1}{c|}{} & Mean $D$ & SD \\
\hline Niosomes N3 & 0.16 & 0.01 \\
\hline $\begin{array}{c}\text { Nioplexes } \\
\text { N3/pEGFP-CFTR } \\
5 / 1\end{array}$ & 0.35 & 0.01 \\
\hline $\begin{array}{c}\text { Nioplexes } \\
\text { N3/pGM169 } \\
\text { 5/1 }\end{array}$ & 0.25 & 0.01 \\
\hline
\end{tabular}

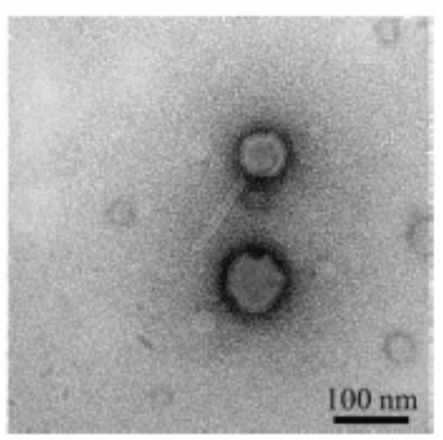

Fig. 6. Physicochemical characterization of N3 niosomes and their corresponding nioplexes vectoring pEGFP-CFTR and pGM169 at 5/1 of cationic lipid/DNA mass ratio. A. Overview of the physicochemical characterization process. B. Particle size (bars) and zeta potential (dots). Each value represents the mean \pm SD of three measurements. C. Dispersity $(Đ)$ values. Each value represents the mean \pm SD of three measurements. D. TEM image of $\mathrm{N} 3$ niosomes. Scale bar: $100 \mathrm{~nm}$.

\subsection{CFTR expression and chloride channel biological activity}

Transfection efficiency assays in human CF airway epithelial cells exposed to N3 nioplexes vectoring pEGFP-CFTR at 5/1 cationic lipid/ DNA mass ratio (Fig. $7 A$ ) revealed $16.34 \pm 0.41 \%$ of EGFP expressing positive live cells, with a cellular viability of $99.48 \pm 3.24 \%$ (data not shown). The immunoblot upon transfection of human CF airway epithelial cells with N3 vectoring pGM169 at cationic lipid/DNA mass ratio 5/1, showed an intense band at approximately $170 \mathrm{KDa}$ that corresponded to the glycosylated CFTR 
protein (Fig. 7B). Band intensity normalization with $\beta$-actin confirmed 5 -fold higher ( $p \leq 0.05$ ) CFTR protein levels in transfected cells compared with non-transfected cells (Fig. 7C).

Regarding CFTR channel biological activity, mean fluorescence signal resulting from the iodide efflux raised remarkably after the addition of CAMP agonists FSK and IBMX (Fig. 7D). Fluorescence signal continued to increase progressively, achieving 1.5-fold higher mean fluorescence peak values ( $p$ $\leq 0.01$ ) in N3/pGM169 transfected versus non-transfected CF cells, until the addition of Nal buffer, when fluorescent signal decreased to baseline values.

A)

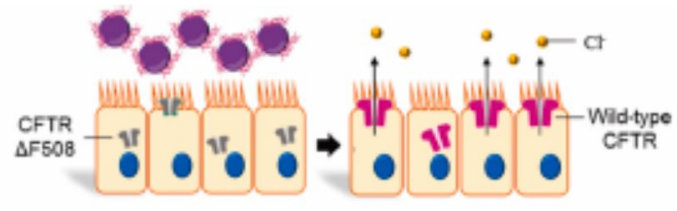

B)

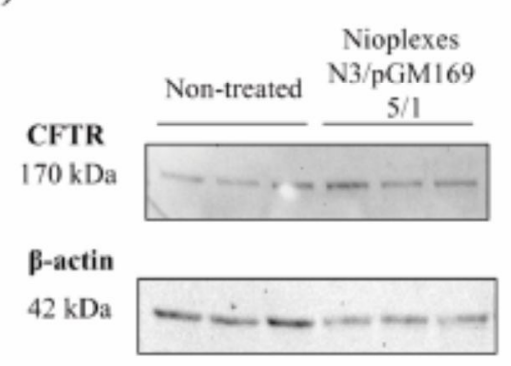

C)

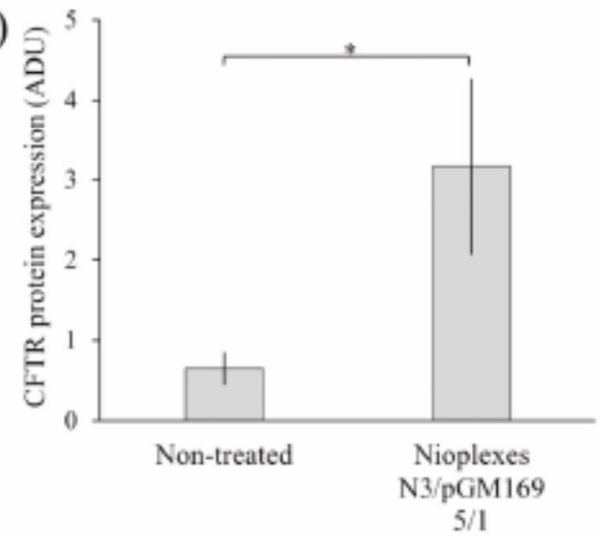

D)
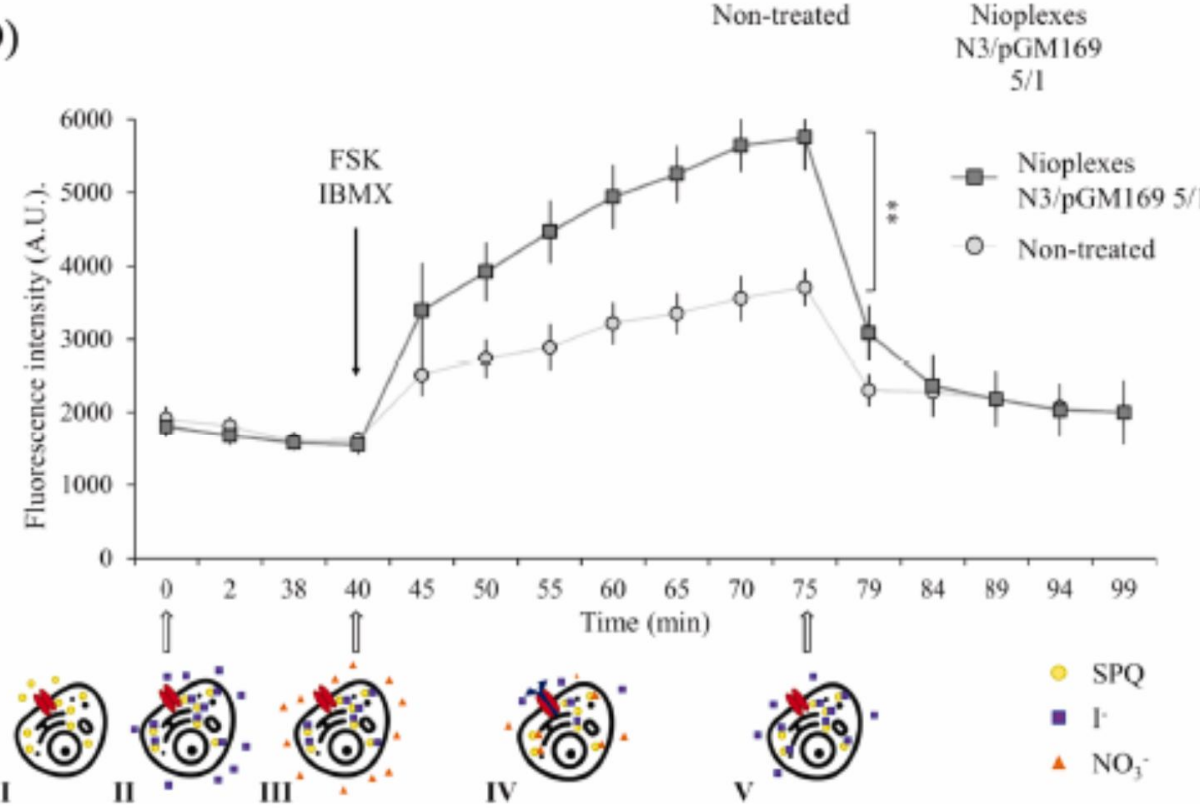

Fig. 7. Evaluation of the expression and the biological activity of the CFTR protein produced by human CF airway epithelial cells transfected with N3 nioplexes vectoring pGM169 at 5/1 cationic lipid/DNA mass ratio, compared with non-transfected ones. A. General scheme of the transfection process. B. CFTR and $\beta$-actin (loading control) bands, analysed by Western Blot. C. $\mathrm{CFTR} / \beta$-actin protein expression ratio. Each value represents the mean \pm $\mathrm{SD}, \mathrm{n}=3$. D. CFTR chloride channel activity determined by the rate of iodide efflux monitored with the fluorescence SPQ molecule. General scheme of the performed functional assay: (D-I) SPQ loading into human CF 
cells; (D-II) quenching of SPQ by I- of the Nal buffer; (D-III) addition of nitrate buffer containing $\mathrm{NO}_{3}-$ and CFTR channel agonists forskolin (FSK) and 3-isobutyl-1-methylxanthine (IBMX), indicated by a black arrow; (D-IV) exit of I- from human CF cells across the CFTR channel and dequenching of SPQ; and (D-V) addition of I- from Nal buffer and secondary quenching of $S P Q$. Each value represents the mean $\pm S D, n>3$. Statistical significance $* * \mathrm{p} \leq 0.01$.

\section{DISCUSSION}

The basic concept of gene therapy involves the addition of a healthy copy of a gene into target cells in order to cure, prevent or slow down the progression of a disease. Unlike most conventional therapeutic approaches, gene therapy aims to correcting the underlying cause of the disease instead of treating its symptoms. Due to its monogenic nature, CF disease is a good candidate for this technology, since the transfer of a healthy copy of the CFTR gene would override the wide variety of mutations present in the genome of CF patients. The delivery of large genetic sequences, such as the CFTR gene, requires efficient vector systems able to transport the DNA into target cells. To date, most of the published clinical trials for CF that use non-viral approaches are based on liposomes (Griesenbach et al., 2015). However, these studies usually healthy animal models in the preclinical stages, both with little relevance for CF disease. In this concern, our study aims to provide exhaustive data regarding niosome mediated CFTR gene delivery efficiency, protein expression and chloride channel functionality in specific CF patient derived airway epithelial cells homozygous for the $\Delta \mathrm{F} 508$ mutation.

In this work, three different cationic lipid based niosome formulations were prepared and evaluated, and the most suitable one according to physicochemical and biological properties to transfer correct copies of the CFTR gene into human CF cells was selected. Different combinations and quantities of the niosome components affect to the gene transfer ability and cell tolerance of the formulations. In this sense, the components used in this work to prepare N1, N2 and N3 niosome formulations presented suitable characteristics for gene therapy purposes according to previous studies. In fact, the cationic lipids DOTMA and tailor-synthesized DTPA have previously reported high efficiency for gene delivery in vitro and in vivo (Mashal et al., 2017; Puras et al., 2014). As a helper component, squalene based niosomes have proven efficiency to transfect retinal cells (Ojeda et al., 2016), while chloroquine has the ability to prevent endosomal acidification as well as to inhibit lysosomal enzymes that could damage the genetic material (Cheng et al., 2006; Sanz et al., 2012). In addition, it is well known the suitability of non-ionic surfactants polysorbate 20 (VillateBeitia et al., 2018), polysorbate 80 (Puras et al., 2014) and poloxamer 407 (Monti et al., 2010) for gene delivery purposes.

Physicochemical characterization of niosomes in terms of size, zeta potential, dispersity and morphology is useful to predict the potential applicability of these formulations for gene therapy purposes. In this regard, N1, N2 and N3 niosomes and nioplexes revealed mean particl sizes between $100 \mathrm{~nm}$ and $200 \mathrm{~nm}$, appropriate for nucleic acid delivery (Andar et al., 2014). In fact, mean particle size can determine cellular uptake, being bigger size particles ( $>500 \mathrm{~nm}$ ) more difficult and slowly taken, contrary to 
smaller particles ( $<40 \mathrm{~nm}$ ), which are easily and rapidly captured (dos Santos et al., 2011). Regarding zeta potential, the three niosome formulations showed positive values which promote electrostatic interactions with negatively charged DNA to form nioplexes (Hosseinkhani and Tabata, 2006). In addition, positive surface charges above $+20 \mathrm{mV}$ presented by N1, N2 and N3 formulations prevent particle aggregation and enhance cellular uptake (Caracciolo and Amenitsch, 2012). As expected, zeta potential values declined after the addition of DNA at the low cationic lipid/DNA mass ratio $2 / 1$, demonstrating a partial neutralization of surface charges due to the electrostatic interactions between the amine groups of the cationic lipids and the phosphate groups of the DNA (Paecharoenchai et al., 2012).

Once physicochemically characterized, we evaluated the biological performance of N1, N2 and N3 formulations vectoring the reporter pEGFP in human CF airway epithelial cells. Regarding cell viability, N3 nioplexes showed excellent values above $90 \%$, while N1 and N2 were worse tolerated. Considering that N1 and N2 share the same cationic lipid DOTMA and helper lipid squalene, these results suggested that the components used to elaborate N3 niosomes were more suitable for gene therapy applied to human CF cells. Concerning transfection efficiency in terms of EGFP expression, we found that N3 nioplexes, mainly at the cationic lipid/DNA mass ratio $5 / 1$, presented significantly higher values than its counterparts. In fact, the chloroquine component present in N3 may enhance its endosomal escape and, therefore, improve the intracellular delivery of the genetic cargo (Xie et al., 2018). Hence, based on those cell viability and transfection efficiency results, we selected the N3 formulation for the following studies in human CF airway epithelial cells.

The evaluation of cellular uptake is a primary assay that helps to understand part of the transfection process and shows the capacity of the nioplexes to be internalized when they are in contact with the cells. The $80 \%$ of cellular internalization obtained after $4 \mathrm{~h}$ incubation with N3 nioplexes at 5/1 mass ratio supported the high transfection values obtained. In order to further understand the transfection process of N3 nioplexes, we studied the intracellular trafficking pathways followed by this formulation. In general, most non-viral vectors enter the cells via endocytosis, being CME and CvME the best studied endocytic pathways (Rejman et al., 2004). Although there is no a clear consensus, the CVME has been generally described as a non-acidic and non-digestive pathway (Nichols, 2003), while it is considered that the CME pathway integrates the endocyted vesicles into late endosomes (Luzio et al., 2009). On the other hand, it has been described that the acid $\mathrm{pH}$ in lysosomes causes the degradation of non-viral vector/DNA complexes (Khalil et al., 2006). Here, we found that the N3 formulation followed predominantly both the CVME and the macropinocytic pathways, pointing out to the non-acidic and non-digestive hypothesis of the CVME pathway. This is consistent with the superior fluorescent signal observed with CVME and macropinocytosis markers compared to CME markers in human CF cells, which would suggest a higher presence of these endocytic vesicles in this cell type. These results, together with the ability of the chloroquine component of N3 to enhance endosomal escape, would contribute to explain the high transfection efficiency of this formulation in human CF cells. In this regard, it is also known that chloroquine, by itself, can enhance transfection efficiency whenever included to the cell culture 
medium or incorporated into cationic-peptide-DNA complexes (Yang et al., 2009) in a dose-dependent matter. However, the pretreatment with chloroquine, has shown high toxicity levels that limit further clinical applications (Zhang et al., 2003). For this reason, chloroquine was incorporated within the niosome formulation in order to avoid such deleterious effect. Such inclusion of chloroquine into a niosome formulation, rather than as a co-/pre-treatment of cells, would be a more logical approach for in vivo settings.

Once fully characterized and corroborated the suitability of N3 formulation for gene delivery purposes in CF cells, this niosome was complexed to the therapeutic CFTR gene constructs at the cationic lipid/DNA mass ratio $5 / 1$. The physicochemical analysis corroborated suitable particle size, $Đ$, surface charge and morphology. As expected, N3/pGM169 nioplexes showed a slight increase in zeta potential values, probably due to the lack of CpG islets of that plasmid. We evaluated the transfection efficiency of the N3/pGM169 formulation in terms of CFTR protein expression, which in consequence would mean a correct translation of the delivered CFTR gene into protein. We obtained glycosylated CFTR protein bands in accordance with previous studies (Garbuzenko et al., 2019; Hyde et al., 2008). The increment of CFTR protein expression was of 5-fold respect to nontransfected cells, which would correspond to an equal or superior increase at the mRNA level. According to previous reports, $5 \%$ of wild CFTR mRNA is enough to correct the chloride ion transport defect in mice (Dorin et al., 1996; Harvey et al., 1999). Importantly, the high CFTR protein expression levels obtained in this work lead to $55 \%$ increment (corresponding to approximately 1.5 -fold) of the chloride channel functionality, which, according to the literature, would largely exceed the values needed to provide therapeutic benefits (Dorin et al., 1996; Ramalho et al., 2002). Of note, previous studies in this field obtained lower rates of CFTR functionality measured by iodide efflux monitoring. For instance, the use of the same therapeutic pGM169 genetic construct employed in this work but complexed to the commercial liposome Lipofectamine ${ }^{\mathrm{TM}}$ 2000, achieved an increment of around $25 \%$ in CFTR channel activity in HEK-293 transfection model cells (Hyde et al., 2008). Other authors reported an increment of around $36 \%$ in CF cells transfected with lipid nanoparticles vectoring a modified CFTR mRNA (Robinson et al., 2018). Although in an initial stage, our thorough research holds great relevance, mainly considering that we reached high levels of CFTR protein and chloride channel functionality in CF patient derived airway epithelial cells, employing for the first time niosomes as a non-viral gene therapy strategy for this disease.

\section{CONCLUSIONS}

In conclusion, our data demonstrate that: (i) N3 niosomes present suitable physicochemical properties for gene delivery purposes and are able to efficiently transfect human cystic fibrosis airway epithelial cells, (ii) N3 based nioplexes followed the caveolae-mediated endocytic route, (iii) transfection with N3 complexed with the therapeutic CFTR gene construct results in a 5-fold increase at protein level and (iv) this transfection leads to a $55 \%$ increment of the chloride channel functionality in human cystic fibrosis airway epithelial cells, pointing out to a potential therapeutic benefit. 


\section{CRediT authorship contribution statement}

Myriam Sainz-Ramos: Conceptualization, Methodology, Formal analysis, Investigation, Writing - review \& editing, Visualization. Ilia Villate-Beitia: Conceptualization, Methodology, Formal analysis, Writing original draft, Visualization. I doia Gallego: Conceptualization, Methodology, Formal analysis, Writing - original draft, Visualization. Nuseibah A.L. Qtaish: Methodology, Investigation. Tania B. LopezMendez: Conceptualization, Methodology, Investigation. Ramón Eritja: Resources, Writing - review \& editing. Santiago Grijalvo: Resources, Writing - review \& editing. Gustavo Puras: Conceptualization, Methodology, Writing - review \& editing, Supervision, Project administration. José Luis Pedraz: Conceptualization, Methodology, Writing - review \& editing, Supervision, Project administration, Funding acquisition.

\section{Declaration of Competing I nterest}

The authors declare that they have no known competing financial interests or personal relationships that could have appeared to influence the work reported in this paper.

\section{ACKNOWLEDGMENTS}

Authors wish to thank: ICTS "NANBIOSIS", specifically the Drug Formulation Unit (U10) of the CIBER in Bioengineering, Biomaterials and Nanomedicine (CIBER-BBN) for the intellectual and technical assistance; SGIker (UPV/EHU) for technical and human support; the Department of Education, University and Research of the Basque Country Government (Consolidated Groups, IT907-16), the Spanish Ministry of Science and Innovation (Grant PID2019-106199RB-C21); the Cystic Fibrosis Association of the Basque Country; the Unit of Viral Infections and Comparative Pathology at the University of Lyon 1 and UK Cystic Fibrosis Gene Therapy Consortium for kindly providing the gene constructs used in this work: pEGFP-CFTR and pGM169, respectively. M.S.R. thanks the University of the Basque Country (UPV/EHU) for the granted pre-doctoral fellowship (PIF17/79). I.V.B. thanks the University of the Basque Country (UPV/EHU) for the granted postdoctoral fellowship (ESPDOC19/47).

\section{Funding source declaration}

This work was supported by the University of Basque Country (UPV/EHU) (pre-doctoral grant PIF17/79 and post-doctoral grant ESPDOC19/47), the Department of Education, University and Research of the Basque Country Government (Consolidated Groups, IT907-16), the Spanish Ministry of Science and Innovation (Grant PID2019-106199RBC21); and the Cystic Fibrosis Association of the Basque Country.

\section{References}

Alton, E.W.F.W., Armstrong, D.K., Ashby, D., Bayfield, K.J., Bilton, D., Bloomfield, E.V., Boyd, A.C., Brand, J., Buchan, R., Calcedo, R., Carvelli, P., Chan, M., Cheng, S.H., Collie, D.D.S., Cunningham, S., Davidson, H.E., Davies, G., Davies, J.C., Davies, L.A., Dewar, M.H., Doherty, A., Donovan, J., Dwyer, N.S., Elgmati, H.I., Featherstone, R.F., Gavino, J., Gea-Sorli, S., Geddes, D.M., Gibson, J.S.R., Gill, D.R., Greening, A.P., Griesenbach, U., Hansell, D.M., Harman, K., Higgins, T.E., Hodges, S.L., Hyde, S.C., 
Hyndman, L., Innes, J.A., Jacob, J., Jones, N., Keogh, B.F., Limberis, M.P., Lloyd- Evans, P., Maclean, A.W., Manvell, M.C., McCormick, D., McGovern, M., McLachlan, G., Meng, C., Montero, M.A., Milligan, H., Moyce, L.J., Murray, G.D., Nicholson, A.G., Osadolor, T., Parra-Leiton, J., Porteous, D.J., Pringle, I.A., Punch, E.K., Pytel, K.M., Quittner, A.L., Rivellini, G., Saunders, C.J., Scheule, R.K., Sheard, S., Simmonds, N.J., Smith, K., Smith, S.N., Soussi, N., Soussi, S., Spearing, E.J., Stevenson, B.J., Sumner- Jones, S.G., Turkkila, M., Ureta, R.P., Waller, M.D., Wasowicz, M.Y., Wilson, J.M., Wolstenholme-Hogg, P., 2015. UK Cystic Fibrosis Gene Therapy Consortium Repeated nebulisation of non-viral CFTR gene therapy in patients with cystic fibrosis: a randomised, double-blind, placebo-controlled, phase $2 \mathrm{~b}$ trial. Lancet Respir. Med. 3, 684-691. https://doi.org/10.3310/eme03050.

Andar, A.U., Hood, R.R., Vreeland, W.N., Devoe, D.L., Swaan, P.W., 2014. Microfluidic preparation of liposomes to determine particle size influence on cellular uptake mechanisms. Pharm. Res. 31, 401-413. https: //doi.org/10.1007/s11095-013-1171-8.

Bartelds, R., Nematollahi, M.H., Pols, T., Stuart, M.C.A., Pardakhty, A., Asadikaram, G., Poolman, B., 2018. Niosomes, an alternative for liposomal delivery. PLoS ONE 13, e0194179.

https://doi.org/10.1371/journal. pone.0194179.

Buchanan, P.J., McNally, P., Harvey, B.J., Urbach, V., 2013. Lipoxin A(4)mediated KATP potassium channel activation results in cystic fibrosis airway epithelial repair. Am. J. Physiol. Lung Cell. Mol. Physiol. 305, L193-L201. https: // doi. org/ 10.1152/ ajplung.00058.2013.

Caracciolo, G., Amenitsch, H., 2012. Cationic liposome/DNA complexes: from structure to interactions with cellular membranes. Eur. Biophys. J. 41, 815-829. https://doi. org/10.1007/s00249-012-0830-8.

Cheng, J., Zeidan, R., Mishra, S., Liu, A., Pun, S.H., Kulkarni, R.P., Jensen, G.S., Bellocq, N.C., Davis, M.E., 2006. Structure-function correlation of chloroquine and analogues as transgene expression enhancers in nonviral gene delivery. J. Med. Chem. 49, 6522-6531.

https: // doi.org/10.1021/jm060736s.

Choi, W.J., Kim, J.K., Choi, S.H., Park, J.S., Ahn, W.S., Kim, C.K., 2004. Low toxicity of cationic lipid-based emulsion for gene transfer. Biomaterials 25, 5893-5903. https://doi.org/10.1016/j.biomaterials.2004.01.031.

Cooney, A.L., McCray Jr, P.B., Sinn, P.L., 2018. Cystic fibrosis gene therapy: looking back. Looking Forward. Genes (Basel) 9https://doi.org/10.3390/genes9110538. doi: E538 [pii].

Dabkowska, A.P., Barlow, D.J., Campbell, R.A., Hughes, A.V., Quinn, P.J., Lawrence, M.J., 2012. Effect of helper lipids on the interaction of DNA with cationic lipid monolayers studied by specular neutron reflection. Biomacromolecules 13, 2391-2401. https://doi.org/10.1021/bm300639n.

Donnelley, M., Parsons, D.W., 2018. Gene therapy for cystic fibrosis lung disease: overcoming the barriers to translation to the clinic. Front. Pharmacol. 9, 1381. https:// doi.org/10.3389/fphar.2018.01381.

Dorin, J.R., Farley, R., Webb, S., Smith, S.N., Farini, E., Delaney, S.J., Wainwright, B.J., Alton, E.W., Porteous, D.J., 1996. A demonstration using mouse models that successful gene therapy for cystic fibrosis requires only partial gene correction. Gene Ther. 3, 797-801.

dos Santos, T., Varela, J., Lynch, I., Salvati, A., Dawson, K.A., 2011. Quantitative assessment of the comparative nanoparticle-uptake efficiency of a range of cell lines. Small 7, 3341-3349. 
https://doi.org/10.1002/smll.201101076.

Dunbar, C.E., High, K.A., Joung, J.K., Kohn, D.B., Ozawa, K., Sadelain, M., 2018. Gene therapy comes of age. Science 359. https: //doi.org/10.1126/science. aan4672. doi: eaan4672 [pii].

Gallego, I., Villate-Beitia, I., Martinez-Navarrete, G., Menendez, M., LopezMendez, T., Soto-Sanchez, C., Zarate, J., Puras, G., Fernandez, E., Pedraz, J.L., 2019. Non-viral vectors based on cationic niosomes and minicircle DNA technology enhance gene delivery efficiency for biomedical applications in retinal disorders. Nanomedicine 17, 308-318 S1549-9634(19)30034-6 [pii]. Garbuzenko, O.B., Kbah, N., Kuzmov, A., Pogrebnyak, N., Pozharov, V., Minko, T., 2019. Inhalation treatment of cystic fibrosis with lumacaftor and ivacaftor co-delivered by nanostructured lipid carriers. J. Control. Release 296, 225-231 S0168-3659(19) 30052-5 [pii].

Griesenbach, U., Pytel, K.M., Alton, E.W., 2015. Cystic fibrosis gene therapy in the UK and elsewhere. Hum. Gene Ther. 26, 266-275. https://doi.org/10.1089/hum.2015.027.

Harvey, B.G., Leopold, P.L., Hackett, N.R., Grasso, T.M., Williams, P.M., Tucker, A.L., Kaner, R.J., Ferris, B., Gonda, I., Sweeney, T.D., Ramalingam, R., Kovesdi, I., Shak, S., Crystal, R.G., 1999. Airway epithelial CFTR mRNA expression in cystic fibrosis patients after repetitive administration of a recombinant adenovirus. J. Clin. Invest. 104, 1245-1255. https: //doi.org/10.1172/J Cl7935.

Hosseinkhani, H., Tabata, Y., 2006. Self assembly of DNA nanoparticles with polycations for the delivery of genetic materials into cells. J. Nanosci. Nanotechnol. 6, 2320-2328. https://doi.org/10.1166/jnn.2006.507.

Hyde, S.C., Pringle, I.A., Abdullah, S., Lawton, A.E., Davies, L.A., Varathalingam, A., Nunez-Alonso, G., Green, A.M., Bazzani, R.P., SumnerJones, S.G., Chan, M., Li, H., Yew, N.S., Cheng, S.H., Boyd, A.C., Davies, J.C., Griesenbach, U., Porteous, D.J., Sheppard, D.N., Munkonge, F.M., Alton, E.W., Gill, D.R., 2008. CpG-free plasmids confer reduced inflammation and sustained pulmonary gene expression. Nat. Biotechnol. 26, 549-551. https://doi.org/10.1038/nbt1399.

Karmali, P.P., Chaudhuri, A., 2007. Cationic liposomes as non-viral carriers of gene medicines: resolved issues, open questions, and future promises. Med. Res. Rev. 27, 696-722. https://doi.org/10.1002/med.20090.

Khalil, I.A., Kogure, K., Akita, H., Harashima, H., 2006. Uptake pathways and subsequent intracellular trafficking in nonviral gene delivery. Pharmacol. Rev. 58, 32-45 58/1/32 [pii].

Liu, F., Yang, J., Huang, L., Liu, D., 1996. Effect of non-ionic surfactants on the formation of DNA/emulsion complexes and emulsion-mediated gene transfer. Pharm. Res. 13, 1642-1646.

https: // doi.org/10.1023/a: 1016480421204.

Luzio, J.P., Parkinson, M.D., Gray, S.R., Bright, N.A., 2009. The delivery of endocytosed cargo to lysosomes. Biochem. Soc. Trans. 37, 1019-1021. https://doi.org/10.1042/BST0371019.

Mashal, M., Attia, N., Puras, G., Martinez-Navarrete, G., Fernandez, E., Pedraz, J.L., 2017. Retinal gene delivery enhancement by lycopene incorporation into cationic niosomes based on DOTMA and polysorbate 60 . J. Control. Release 254, 55-64 S0168- 3659(17)30491-1 [pii].

Mitomo, K., Griesenbach, U., Inoue, M., Somerton, L., Meng, C., Akiba, E., Tabata, T., Ueda, Y., Frankel, G.M., Farley, R., Singh, C., Chan, M., Munkonge, F., Brum, A., Xenariou, S., Escudero-Garcia, S., Hasegawa, M., 
Alton, E.W., 2010. Toward gene therapy for cystic fibrosis using a lentivirus pseudotyped with Sendai virus envelopes. Mol. Ther. 18, 1173-1182. https://doi.org/10.1038/mt.2010.13.

Monti, D., Burgalassi, S., Rossato, M.S., Albertini, B., Passerini, N., Rodriguez, L., Chetoni, P., 2010. Poloxamer 407 microspheres for orotransmucosal drug delivery. Part II: In vitro/in vivo evaluation. Int. J. Pharm. 400, 32-36. https://doi.org/10.1016/j.ijpharm.2010.08.018.

Nichols, B., 2003. Caveosomes and endocytosis of lipid rafts. J. Cell Sci. 116, 4707-4714. https://doi.org/10.1242/jcs.00840.

Ojeda, E., Puras, G., Agirre, M., Zarate, J., Grijalvo, S., Eritja, R., MartinezNavarrete, G., Soto-Sanchez, C., Diaz-Tahoces, A., Aviles-Trigueros, M., Fernandez, E., Pedraz, J.L., 2016. The influence of the polar head-group of synthetic cationic lipids on the transfection efficiency mediated by niosomes in rat retina and brain. Biomaterials 77, 267-279.

https://doi.org/10.1016/j. biomaterials.2015.11.017.

Paecharoenchai, O., Niyomtham, N., Ngawhirunpat, T., Rojanarata, T., Yingyongnarongkul, B.E., Opanasopit, P., 2012. Cationic niosomes composed of spermine-based cationic lipids mediate high gene transfection efficiency. J. Drug Target. 20, 783-792.

https://doi.org/10.3109/1061186X.2012.716846.

Pezzoli, D., Chiesa, R., De Nardo, L., Candiani, G., 2012. We still have a long way to go to effectively deliver genes!. J. Appl. Biomater. Funct. Mater. 10, 82-91. https://doi.org/10.5301/JABFM.2012.9707.

Puras, G., Mashal, M., Zarate, J., Agirre, M., Ojeda, E., Grijalvo, S., Eritja, R., Diaz- Tahoces, A., Martinez Navarrete, G., Aviles-Trigueros, M., Fernandez, E., Pedraz, J.L., 2014. A novel cationic niosome formulation for gene delivery to the retina. J. Control. Release 174, 27-36. https://doi.org/10.1016/j.jconrel.2013.11.004.

Ramalho, A.S., Beck, S., Meyer, M., Penque, D., Cutting, G.R., Amaral, M.D., 2002. Five percent of normal cystic fibrosis transmembrane conductance regulator mRNA ameliorates the severity of pulmonary disease in cystic fibrosis. Am. J. Respir. Cell Mol. Biol. 27, 619-627. https://doi. org/ 10.1165/ rcmb.2001-00040C.

Rejman, J., Oberle, V., Zuhorn, I.S., Hoekstra, D., 2004. Size-dependent internalization of particles via the pathways of clathrin- and caveolae mediated endocytosis. Biochem. J. 377, 159-169.

https: //doi.org/10.1042/BJ 20031253.

Robinson, E., MacDonald, K.D., Slaughter, K., McKinney, M., Patel, S., Sun, C., Sahay, G., 2018. Lipid nanoparticle-delivered chemically modified mrna restores chloride secretion in cystic fibrosis. Mol. Ther. 26, 2034-2046 S1525-0016(18)30217-X [pii].

Sanz, V., Coley, H.M., Silva, S.R., McFadden, J., 2012. Protamine and chloroquine enhance gene delivery and expression mediated by RNAwrapped single walled carbon nanotubes. J. Nanosci. Nanotechnol. 12, 1739-1747. https://doi.org/10.1166/jnn.2012.5172.

van Steensel, B., van Binnendijk, E.P., Hornsby, C.D., van der Voort, H.T., Krozowski, Z.S., de Kloet, E.R., van Driel, R., 1996. Partial colocalization of glucocorticoid and mineralocorticoid receptors in discrete compartments in nuclei of rat hippocampus neurons. J. Cell Sci. 109 (Pt 4), 787- 792.

Villate-Beitia, I., Gallego, I., Martinez-Navarrete, G., Zarate, J., LopezMendez, T., Soto- Sanchez, C., Santos-Vizcaino, E., Puras, G., Fernandez, E., Pedraz, J.L., 2018. Polysorbate 20 non-ionic surfactant enhances retinal 
gene delivery efficiency of cationic niosomes after intravitreal and subretinal administration. Int. J. Pharm. 550, 388-397 S0378-5173(18)30508-8 [pii]. Xie, Y., Yu, F., Tang, W., Alade, B.O., Peng, Z.H., Wang, Y., Li, J., Oupicky, D., 2018. Synthesis and evaluation of chloroquine-containing DMAEMA copolymers as efficient anti-miRNA delivery vectors with improved endosomal escape and antimigratory activity in cancer cells. Macromol. Biosci. 18https://doi.org/10.1002/mabi.201700194. Epub 2017 Aug 4.

Yang, S., Coles, D.J., Esposito, A., Mitchell, D.J., Toth, I., Minchin, R.F., 2009. Cellular uptake of self-assembled cationic peptide-DNA complexes: multifunctional role of the enhancer chloroquine. J. Control. Release 135, 159-165. https://doi.org/10.1016/j.jconrel.2008.12.015.

Zhang, X., Sawyer, G.J., Dong, X., Qiu, Y., Collins, L., Fabre, J.W., 2003. The in vivo use of chloroquine to promote non-viral gene delivery to the liver via the portal vein and bile duct. J. Gene Med. 5, 209-218. https: //doi.org/ 10.1002/jgm. 340. 